\title{
BMJ Open Core and optional infant and young child feeding indicators in Sub-Saharan Africa: a cross-sectional study
}

\author{
Samson Gebremedhin
}

To cite: Gebremedhin S. Core and optional infant and young child feeding indicators in Sub-Saharan Africa: a crosssectional study. BMJ Open 2019;9:e023238. doi:10.1136/ bmjopen-2018-023238

- Prepublication history and additional material for this paper are available online. To view these files, please visit the journal online (http://dx.doi org/10.1136/bmjopen-2018023238).

Received 27 March 2018 Revised 17 December 2018 Accepted 18 December 2018

\section{Check for updates}

(C) Author(s) (or their employer(s)) 2019. Re-use permitted under CC BY-NC. No commercial re-use. See rights and permissions. Published by BMJ.

School of Public Health, Hawassa University, Hawassa, Ethiopia

Correspondence to Dr Samson Gebremedhin; samsongmgs@yahoo.com

\section{ABSTRACT}

Objective The objective of the study is to determine the status of infant and young child feeding (IYCF) in SubSaharan Africa (SSA) based on multiple indicators.

Design Secondary data analysis of 32 Demographic and Health Surveys conducted in SSA since 2010.

Setting Thirty-two countries in SSA.

Participants 151575 infants and young children born in the preceding 2 years of the surveys.

Indicators determined Eight core and six optional IYCF indicators.

Results Majority (95.8\%) of the children born in the preceding 24 months were ever breastfed, and $50.5 \%$ initiated breastfeeding within the first hour of birth. Among infants $0-5$ months of age, $72.3 \%$ were predominantly breastfed and $41.0 \%$ were exclusively breastfed. Continued breastfeeding at 1 year $(89.5 \%)$ was reasonably high, but only $53.7 \%$ continued breastfeeding at 2 years and $60.4 \%$ had age-appropriate breastfeeding. About two-thirds (69.3\%) of infants 6-8 months of age received solid, semisolid or soft food over the previous day across the countries. Among children 6-23 months of age, $41.9 \%$ met the minimum recommended meal frequency, while smaller proportions satisfied the minimum dietary diversity $(21.0 \%)$ and acceptable diet $(9.8 \%)$. About onethird (37.6\%) of children 6-23 months of age consumed iron-rich or iron-fortified food over the previous day. Among non-breastfed children, only $15.0 \%$ received the recommended two or more milk feedings. Thirteen per cent were fed with a bottle with a nipple in the previous day. Country-level estimates for most indicators showed remarkable variations. Yet the minimum dietary diversity and acceptable diet indicators were consistently low. Conclusion Most breastfeeding-related indicators, except exclusive and early initiation of breastfeeding, are in an acceptable level in SSA. However, complementary feeding indicators are generally low.

\section{BACKGROUND}

Between 1990 and 2016, globally the total number of deaths under the age of 5 dropped by $56 \% .^{12}$ Yet the figure falls short of the Millennium Development Goal 4, which targeted for a two-thirds reduction between 1990 and $2015 .^{23}$ Globally every year 41 childhood deaths per 1000 live births, equivalent to 5.6 million deaths, happen. The problem

\section{Strengths and limitations of this study}

The study is based on recent and nationally representative surveys conducted in multiple SubSaharan African (SSA) countries.

- The study provided a recent summary of all core and optimal infant and young child feeding indicators that have not been available at this scale before.

- The huge sample size allowed for precise estimation of the indicators, including those defined based on narrow age groups.

- The findings of the study might not be generalisable to other SSA countries that have not been represented in the analysis.

- Due to the cross-sectional nature of the original studies, indicators related to complementary feeding practice could have been affected by seasonality bias.

is especially evident in Sub-Saharan Africa (SSA), where half of the global deaths occur. ${ }^{1}$

Undernutrition is an important underlying cause of mortality and a significant predictor of a child's survival. According to a recent estimate, nutrition-related factors contribute to $45 \%$ of the global under- 5 deaths. ${ }^{4}$ Beyond survival, optimal nutrition is indispensable to children to reach their physical and mental development potentials. Vitamin A deficiency and iodine deficiency disorders remain the leading causes of preventable blindness and mental retardation. Further, stunting, as well as iodine, iron and zinc deficiencies, may limit cognitive development. ${ }^{4}$ Globally, $23 \%$ of children are stunted. ${ }^{5}$ The magnitude of hidden hunger is also high. About $43 \%$ of children are anaemic, 33\% are vitamin A-deficient, $30 \%$ of school children have inadequate iodine intake and $17 \%$ of the global population has insufficient zinc intake. ${ }^{6-9}$

The first 2 years of life are the most critical for the physical and mental development of children. Nutritional deprivation over this period is likely to result in largely irreversible physical and cognitive deficits. Thus, this period is regarded as the "window of 
opportunity' for interventions against undernutrition. ${ }^{1011}$ Conversely, in low-income and middle-income countries including the SSA, this period poses a significant vulnerability to children's well-being. ${ }^{10}$ Especially the complementary feeding period, which extends between 6 and 23 months of age, is characterised by growth retardation and onset of micronutrient deficiencies in many low-income and middle-income countries. ${ }^{12} \mathrm{~A}$ study concluded that promotion of optimal infant and young child feeding (IYCF) practice in the first 2 years could avert up to 220000 childhood deaths each year. ${ }^{13}$

Optimal IYCF has multiple dimensions. Infants should initiate breastfeeding within 1 hour of birth, breastfeed exclusively for the first 6 months and continue to receive breast milk up to 2 years of age and beyond. Starting at 6 months, age-appropriate complementary foods should be introduced with optimal feeding frequency and nutrient density. ${ }^{14}$ In 2008 the WHO proposed a set of core and optional indicators that can be used in population-based surveys for the assessment of IYCF practices and for the evaluation of interventions. ${ }^{14}$ The new standard has replaced a previous guideline ${ }^{15}$ and created a consensus on IYCF indicators and provided methodological standardisation for their measurement. ${ }^{13}$

Since the development of the guideline, the indicators have been widely generated by localised and national population-based surveys. Especially the Demographic and Health Surveys (DHS) presented a special opportunity to measure the indicators in many low-income and middle-income countries using similar and standardised approach. However, pooled indicators for the entire SSA have not been made available so far. Pooled indicators are important to show the critical cross-cutting gaps in IYCF practices in SSA, where malnutrition and child mortality are major concerns. Further, the indicators can be used as background information for the IYCF efforts in the region and may help to track the progress on IYCF and child nutrition. Accordingly, the purpose of the current study is to determine the status of the 14 core and optional IYCF indicators for the SSA region based on the recent DHS conducted since 2010.

\section{METHODS}

\section{Study design}

This descriptive cross-sectional study was conducted based on the secondary data of all 32 recent and nationally representative DHS conducted in the SSA region between 2010 and 2016. The surveys included in the analysis with their respective weighted and unweighted sample sizes are listed in table 1.

\section{Study area description}

According to the World Bank classification, the SSA region includes 48 predominately low-income African countries located south of the Sahara. In 2016 the population size of the region was nearly a billion. Despite the fast economic growth recorded in the region in the last
Table 1 List of countries represented in the analysis and their respective sample size

Sample size $(n=151575)$

\begin{tabular}{lllc} 
Country & Survey year & Unweighted & Weighted \\
\cline { 3 - 4 } Angola & $2015-2016$ & 6553 & 4659 \\
Burkina Faso & 2010 & 7029 & 3394 \\
Benin & $2011-2012$ & 5792 & 1983 \\
\hline Burundi & 2010 & 3465 & 1807 \\
Congo & $2013-2014$ & 8642 & 14213 \\
$\begin{array}{l}\text { (Democratic } \\
\text { Republic) }\end{array}$ & & & \\
\hline
\end{tabular}

\begin{tabular}{llrr}
$\begin{array}{l}\text { Congo (Republic } \\
\text { of the) }\end{array}$ & $2011-2012$ & 4256 & 866 \\
\hline Cote d'Ivoire & $2011-2012$ & 3668 & 4254 \\
\hline Cameroon & 2011 & 5503 & 4010 \\
\hline Ethiopia & 2016 & 4654 & 19087 \\
\hline Gabon & 2012 & 2761 & 345 \\
\hline Ghana & 2014 & 2615 & 5043 \\
\hline Gambia & 2013 & 3754 & 372 \\
\hline Guinea & 2012 & 3339 & 2011 \\
\hline Kenya & 2014 & 4185 & 8335 \\
\hline Comoros & 2012 & 1386 & 144 \\
\hline Liberia & 2013 & 3495 & 744 \\
\hline Lesotho & 2014 & 1517 & 351 \\
\hline Mali & $2012-2013$ & 4620 & 3274 \\
\hline Malawi & $2015-2016$ & 7330 & 3000 \\
\hline Mozambique & 2011 & 5235 & 5153 \\
\hline Nigeria & 2013 & 14847 & 33398 \\
\hline Niger & 2012 & 5634 & 3473 \\
\hline Namibia & 2013 & 2107 & 420 \\
\hline Rwanda & $2014-2015$ & 3431 & 2083 \\
\hline Sierra Leone & 2013 & 5611 & 1198 \\
\hline Senegal & 2016 & 2917 & 2603 \\
\hline Chad & $2014-2015$ & 8080 & 2516 \\
\hline Togo & $2013-2014$ & 3183 & 1300 \\
\hline Tanzania & $2015-2016$ & 4687 & 9390 \\
\hline Uganda & 2011 & 3488 & 6825 \\
\hline Zambia & $2013-2014$ & 5195 & 2842 \\
\hline Zimbabwe & 2015 & 2596 & 2484 \\
\hline & & & \\
\hline
\end{tabular}

two decades, SSA remains the least developed part of the world, with a gross national income (GNI) per capita of US $\$ 3700$. Of the countries in the region, 41 are either low-income or lower middle-income economies, with a GNI of US $\$ 3955$ or less. ${ }^{16}$ SSA has the lowest index of essential health services in the world, and life expectancy at birth is about 60 years. ${ }^{17}$

\section{Eligibility criteria}

All DHS conducted in the SSA since 2010 were eligible for the study. On the other hand, all children who were 


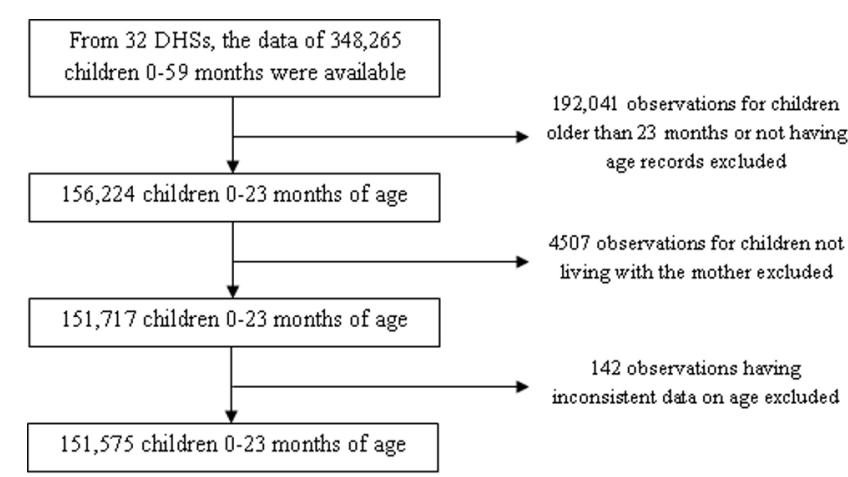

Figure 1 Flow chart of the study. DHS, Demographic and Health Survey.

born within 24 months preceding the surveys, irrespective of being living or deceased, were considered for the analysis. Conversely, data of living children who were not staying with the respondent at the time of the surveys were excluded (figure 1).

\section{Sampling approach of the DHS}

Each DHS is designed to generate representative data at national, place of residence (urban-rural) and subnational (federal or regional states) levels. The sampling is typically based on two-stage cluster sampling approach stratified for place of residence. First, enumeration areas (EA) are drawn from recent national census files, then in each EA selected a complete listing of households is made. Afterwards a sample of 25-30 households are drawn from each EA using systematic random sampling approach. The households that have been selected were visited, household members got enumerated and all the eligible were enrolled in the study. ${ }^{18} 19$ Then data were collected from the three groups of eligible subjects: women and men 15-49 years of age and children 0-59 months of age ${ }^{1819}$ However, this specific analysis included data collected from women in the reproductive age who gave at least one birth in the preceding 24 months of the survey.

\section{Data collection}

Data were collected from the mothers of the index children using standardised and pretested questionnaires prepared in the major local languages of the respective countries. DHS data were collected by interviewers, supervisors and field editors who received an intensive training lasting at least 4 weeks.

The DHS collects a range of IYCF-related information in compatible manner with the existing WHO guideline. ${ }^{14}$ Information gathered included history of ever breastfeeding and timely initiation of breastfeeding for both deceased and living children; breastfeeding, consumption of plain water and other liquids, meal frequency, types of food the child consumed, and practice of bottle feeding over the previous day for all infants and young children living with the respondents; and frequency of milk or formula feeding for all non-breastfed children.
The height and weight of the children were measured using calibrated tools following standard procedures. Stunting, wasting and underweight were defined as height-for-age, weight-for-height and weight-for-age below -2 standardised scores, respectively, whereas children who fell below -3 z-scores were considered severely malnourished.

Among children 6-23 months of age, haemoglobin levels were determined onsite from capillary blood using a portable HemoCue analyser and the measurements were adjusted for altitude. Ultimately, based on the haemoglobin concentration, anaemia status was classified as non-anaemic (above $110 \mathrm{~g} / \mathrm{L}$ ), mild (100-109g/L), moderate $(70-99 \mathrm{~g} / \mathrm{L})$ and severe (less than $70 \mathrm{~g} / \mathrm{L}$ ) following standard threshold values.

\section{Patient and public involvement}

As the study was conducted based on secondary data, patients and/or the public were not involved.

\section{Data analysis}

Initially the 'children's record' data sets for all of the 32 surveys were separately downloaded from the DHS programme website in SPSS V.22 format ${ }^{20}$ and merged into one mega file. Then with the exception of basic sociodemographic and IYCF relevant variables, all the other variables were dropped. Frequency distribution and measures of central tendency and dispersion were used to describe the data. Recoding of children's age, meal frequency and dietary diversity was made following the WHO guideline. ${ }^{14}$ No attempt was made to impute or estimate missing values in the data set.

Data were analysed using weighted data analysis approach. Country-level estimates were weighted using the sampling weight already provided in the DHS data sets. Indicators pooled across the countries were further weighted using poststratification fractions defined based on the 2016 population size of the 32 countries. Further, normalisation of the poststratification weight was made, so that the weighted and unweighted samples would be equal.

Dietary diversity was assessed by asking the mother whether the child had received from 14 different food groups in the preceding day, without setting minimum intake restrictions. During analysis the food groups were recategorised into the basic seven food groups recommended by WHO for infants and young children. The seven food groups were grains, roots and tubers, legumes and nuts, dairy products excluding breast milk, flesh foods (meat, fish, poultry or organ meats), eggs, vitamin A-rich fruits and vegetables, and other fruits and vegetables. ${ }^{14}$ Ultimately, dietary diversity score that ranges from 0 to 7 was computed. Consumptions of sweets, oil, fats or butter have not been counted in the dietary diversity calculation.

The study generated eight core and six optional IYCF indicators for the SSA region as well as for each of the 32 countries included in the study. Age-disaggregated figures were also presented for most of the indicators. 
Table 2 Summary of core and optional indicators generated in the study

\begin{tabular}{|c|c|c|}
\hline Indicators & Numerator & Denominator \\
\hline \multicolumn{3}{|l|}{ Core indicators } \\
\hline Early initiation of breastfeeding & $\begin{array}{l}\text { Children born in the last } 24 \text { months (living or deceased) } \\
\text { who were put to the breast within } 1 \text { hour of birth. }\end{array}$ & $\begin{array}{l}\text { Children born in the last } \\
24 \text { months. }\end{array}$ \\
\hline Exclusive breastfeeding under 6 months & $\begin{array}{l}\text { Infants } 0-5 \text { months who received only breast milk } \\
\text { during the previous day. }\end{array}$ & Infants $0-5$ months. \\
\hline Continued breastfeeding at 1 year & $\begin{array}{l}\text { Children } 12-15 \text { months who received breast milk } \\
\text { during the previous day. }\end{array}$ & Children $12-15$ months. \\
\hline
\end{tabular}

Introduction of solid, semisolid or soft
foods

Minimum dietary diversity

Minimum meal frequency

Minimum acceptable diet

\section{Infants 6-8 months who received solid, semisolid or} soft foods during the previous day.

Children 6-23 months who received foods from 4 or more food groups out of the standard 7 food groups during the previous day.

Children 6-23 months who received solid, semisolid or soft foods the minimum number of times or more during the previous day. ${ }^{*}$

Breastfed children 6-23 months who had at least the minimum dietary diversity and meal frequency, and non-breastfed children 6-23 months who received at least 2 milk feedings and had at least the minimum dietary diversity not including milk feeds and the minimum meal frequency during the previous day.

\section{Children 6-23 months who received an iron-rich food or food that was specially designed for infants and young children and was fortified with iron. \\ Consumption of iron-rich or iron-fortified foods}

\section{Optimal indicators}

\section{Children ever breastfed}

Continued breastfeeding at 2 years

$$
\text { Age-appropriate breastfeeding }
$$

Predominant breastfeeding under 6 months

Bottle feeding
Milk feeding frequency for non-breastfed
children

Children born in the last 24 months (living or deceased) who were ever breastfed.

Children 20-23 months who received breast milk during the previous day.

Infants 0-5 months who received only breast milk plus, Children 6-23 months. children 6-23months who received breast milk as well as foods during the previous day.

Infants 0-5 months of age who received breast milk Infants 0-5 months. as the predominant source of nourishment during the previous day.

\section{Children 0-23 months who were fed with a bottle Children 0-23 months.} during the previous day.

Non-breastfed children 6-23 months of age who received at least 2 milk feedings during the previous day.
Infants 6-8 months.

Children 6-23 months.

Children 6-23 months.

Children 6-23 months.

Children 6-23 months.

Children born in the last 24 months.

Children 20-23 months.

Non-breastfed children

6-23 months.

\footnotetext{
*2 and 3 times for breastfed children 6-8 and 9-23 months, respectively; 4 times for non-breastfed children. The number of milk feeds is counted for non-breastfed children as meals.
}

The manuscript primarily describes the IYCF indicators at the SSA level, while online supplementary file 1 tabulates the summary of the indicators for each of the 32 countries. As summarised in table 2, the indicators were generated as per the recommendation of the WHO guideline (table 2). ${ }^{14}$

Among the IYCF indicators recommended by the WHO, the median duration of breastfeeding was not determined for two reasons: first, unlike the others the indicator requires a different age range (0-35 months of children), and second among children 0-35 months of age more than half $(52 \%)$ were still breastfeeding at the time of the study, hence determining the median duration was not possible.

\section{RESULTS}

Sociodemographic characteristics

The data of 151575 children born in the previous 2 years of the survey were included in the analysis. Most of the 
Table 3 Sociodemographic characteristics of the respondents and the index infants and young children from 32 Sub-Saharan African countries, 2010-2016

\begin{tabular}{lcc}
\hline Variables & Frequency & Percentage \\
\hline Type of place of residence $(n=151575)$ & \\
Urban & 43313 & 28.6 \\
Rural & 108262 & 71.4
\end{tabular}

Age of the mother (years) $(n=151575)$

\begin{tabular}{|c|c|c|}
\hline $15-24$ & 50646 & 33.4 \\
\hline $25-34$ & 70892 & 46.8 \\
\hline $35-49$ & 30037 & 19.8 \\
\hline \multicolumn{3}{|c|}{ Maternal educational status $(n=151566)$} \\
\hline No education & 61650 & 40.7 \\
\hline Primary & 52128 & 34.4 \\
\hline Secondary & 32844 & 21.7 \\
\hline Higher & 4944 & 3.3 \\
\hline \multicolumn{3}{|c|}{ Respondents currently working $(n=151328)$} \\
\hline No & 61693 & 40.8 \\
\hline Yes & 89636 & 59.2 \\
\hline \multicolumn{3}{|l|}{ Marital status $(n=151568)$} \\
\hline Married/Living with partner & 135904 & 89.7 \\
\hline Not ever married & 7561 & 5.0 \\
\hline Separated & 4384 & 2.9 \\
\hline Divorced & 2084 & 1.4 \\
\hline Widowed & 1635 & 1.1 \\
\hline \multicolumn{3}{|c|}{ Husband's/partner's education ( $n=141069)$} \\
\hline No education & 46668 & 33.1 \\
\hline Primary & 43370 & 30.7 \\
\hline Secondary & 38330 & 27.2 \\
\hline Higher & 10090 & 7.2 \\
\hline Don't know & 2610 & 1.9 \\
\hline
\end{tabular}

Children ever born to the respondent $(n=151575)$

\begin{tabular}{ccc}
1 & 28309 & 18.7 \\
$2-4$ & 70967 & 46.8 \\
5 or more & 52300 & 34.5 \\
Number of under-5 children in the household $(\mathrm{n}=151632)$ \\
1 & 53082 & 35.0 \\
2 & 58846 & 38.8 \\
3 or more & 39647 & 26.2 \\
Child alive $(\mathrm{n}=151575)$ & & \\
No & 22695 & 15.0 \\
\hline Yes & 128880 & 85.0 \\
Age (years) $(\mathrm{n}=128880)$ & & \\
\hline 0 & 66748 & 51.8 \\
1 & 62132 & 48.2 \\
\hline Age (months) $(\mathrm{n}=124338)$ & & \\
\hline $0-5$ & 32980 & 26.5 \\
\hline $6-11$ & 33014 & 26.6 \\
\hline
\end{tabular}

Continued
Table 3 Continued

\begin{tabular}{ccl}
\hline Variables & Frequency & Percentage \\
\hline $12-17$ & 32779 & 26.4 \\
$18-23$ & 25566 & 20.6 \\
Sex of the child $(n=151575)$ & & \\
Boys & 77007 & 50.8 \\
Girls & 74569 & 49.2 \\
\hline
\end{tabular}

children $(71.4 \%)$ were selected from rural areas. The mean $( \pm \mathrm{SD})$ age of the mothers was $28.0( \pm 6.9)$ years, and a little less than half (46.8\%) were between 25 and 34 years of age. The vast majority (89.7\%) of the respondents were married or living with their partners.

More than one-third of the respondents $(40.7 \%)$ had no formal education. The median number of children ever born to the mothers was 3 , and nearly one-third (34.5\%) were grandmultiparous. The median number of children under the age of 5 per household was 2 , and $65.0 \%$ had two or more of the children under the age of 5 .

During the surveys, $15 \%$ of children born in the last 24 months were deceased. The mean $( \pm \mathrm{SD})$ age of the living children was $10.9( \pm 6.6)$ months, and the children were almost uniformly distributed across the four age groups, except for a minor under-representation of the age group 18-23 months. The boys to girls ratio was 1.03 (table 3 ).

\section{Prevalence of malnutrition and anaemia}

The three main anthropometric indices were determined for about 93000 infants and young children. Nearly a quarter $(24.1 \%)$ had low height-for-age z-scores (below $-2 \mathrm{SD}$ ), indicating stunting, whereas $9.2 \%$ were severely stunted (below $-3 \mathrm{SD}$ ). More than one-fifth of the children $(22.6 \%)$ were underweight (weight-for-age below $-2 \mathrm{SD}$ ), and $6.0 \%$ were severely underweight. One in ten $(11.9 \%)$ had low weight-for-height z-scores (below -2 SD), suggesting wasting, and $2.4 \%$ were severely wasted. Conversely, based on weight-for-height index, $4.1 \%$ of the infants and young children were overweight or obese (above $+2 \mathrm{SD}$ ).

The haemoglobin concentration values were available for about 40000 children 6-23 months of age. The mean $( \pm$ SD) haemoglobin was $99( \pm 19) \mathrm{g} / \mathrm{L}$. About threefourths $(74.0 \%)$ of the children had some degree of anaemia and $4.2 \%$ were severely anaemic (table 4 ).

\section{Children ever breastfed and early initiation of breastfeeding}

Unlike the other core and optional IYCF indicators, children ever breastfed and early initiation of breastfeeding are determined based on the historical data of children born over the past 2 years, irrespective of being living or deceased at the time of the survey ${ }^{14}$ (figure 2).

Among 150677 children born in the last 24 months, the vast majority $(95.8 \%)$ were ever breastfed at least once before. Among the living children, $99.0 \%$ were ever breastfed, whereas the corresponding figure for the deceased children was lower $(77.1 \%)$. Among the living 
Table 4 Prevalence of undernutrition and anaemia among children 0-23 months old in 32 Sub-Saharan African countries, 2010-2016

\begin{tabular}{|c|c|c|}
\hline Variable & Frequency & Percentage \\
\hline \multicolumn{3}{|l|}{ Height-for-age (z-score) $(n=90490)$} \\
\hline Above $+2 S D$ & 3496 & 3.9 \\
\hline Normal $(-2$ to $+2 \mathrm{SD})$ & 65175 & 72.0 \\
\hline Moderately stunted (-2 to $-3 \mathrm{SD})$ & 13499 & 14.9 \\
\hline Severely stunted (below -3 SD) & 8321 & 9.2 \\
\hline \multicolumn{3}{|l|}{ Weight-for-age (z-score) ( $\mathrm{n}=90490)$} \\
\hline Above $+2 S D$ & 2080 & 2.3 \\
\hline Normal $(-2$ to $+2 S D)$ & 67954 & 75.1 \\
\hline Moderately underweight ( -2 to $-3 \mathrm{SD})$ & 15035 & 16.6 \\
\hline Severely underweight (below $-3 \mathrm{SD}$ ) & 5421 & 6.0 \\
\hline \multicolumn{3}{|l|}{ Weight-for-height (z-score) (n=90 677) } \\
\hline Overweight or obese (above $+2 \mathrm{SD}$ ) & 3748 & 4.1 \\
\hline Normal $(-2$ to +2 SD) & 76141 & 84.0 \\
\hline Moderately wasting ( -2 to $-3 \mathrm{SD}$ ) & 8598 & 9.5 \\
\hline Severely wasting (below -3 SD) & 2191 & 2.4 \\
\hline \multicolumn{3}{|l|}{ Anaemia status $(n=40638)$} \\
\hline Not anaemic & 10556 & 26.0 \\
\hline Mild & 10971 & 27.0 \\
\hline Moderate & 17401 & 42.8 \\
\hline Severe & 1711 & 4.2 \\
\hline
\end{tabular}

children, age-disaggregated data indicated that $99.2 \%$ of infants 0-11 months of age and $98.8 \%$ of children 12-23 months of age were ever breastfed. In all countries except Gabon, the proportion of children ever breastfed exceeded $90 \%$.

Among 136029 children having complete information about timely initiation of breastfeeding, 50.5\% were put to breast immediately or within 1 hour of birth (figure 2). The remaining commenced breastfeeding between 1 and 24 hours of birth or after the first day of birth (12.5\%). Substantial differences were observed with regard to the timely initiation of breastfeeding between living $(52.6 \%)$ and deceased $(28.4 \%)$ children. Further

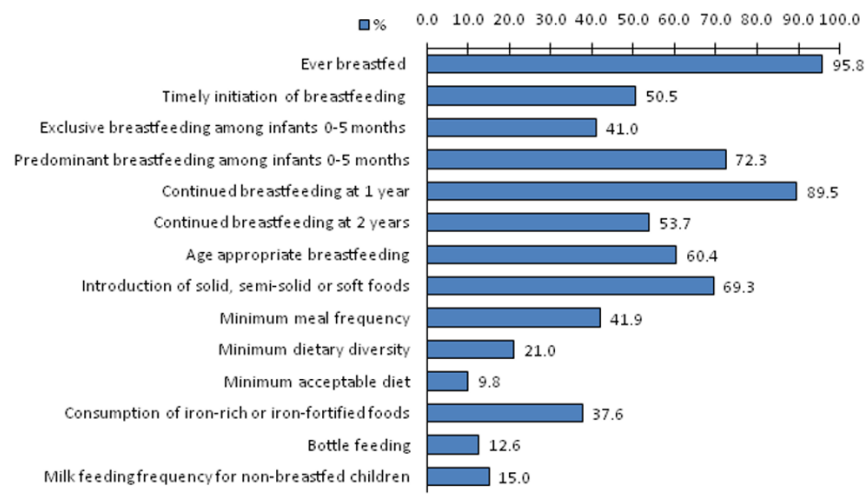

Figure 2 Summary of core and optional infant and young child feeding indicators in 32 Sub-Saharan African countries, 2010-2016.

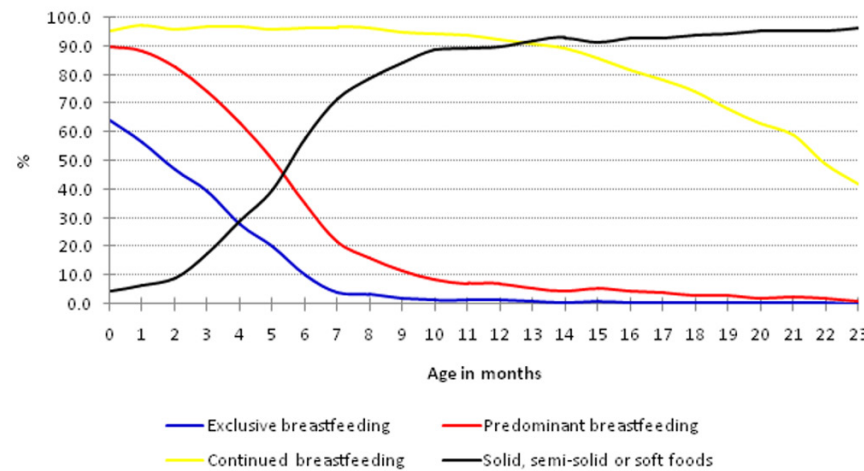

Figure 3 Exclusive, predominant and continued breastfeeding and introduction of food among children 0-23 months of age in 32 Sub-Saharan African countries, 20102016.

disaggregation based on age showed $52.3 \%$ of infants $0-11$ months and $52.8 \%$ of children $12-23$ months initiated breastfeeding within 1 hour of birth. In Rwanda, Mozambique, Malawi, Burundi, Ethiopia and Namibia, more than two-thirds of the children were put to breast timely. Conversely, in Congo Republic and Chad the corresponding figures were below $25 \%$.

\section{Exclusive and predominant breastfeeding}

Among infants younger than 6 months, $41.0 \%$ received only breast milk during the previous day. The exclusive breastfeeding practices among infants $0-1,2-3$ and $4-5$ months were $59.5 \%, 43.1 \%$ and $23.9 \%$, respectively. Exclusive breastfeeding exceeds $70 \%$ in Rwanda, Zambia and Lesotho. Conversely, in Comoros, Cote d'Ivoire, Gabon and Nigeria, less than $20 \%$ of infants $0-5$ months were exclusively breastfed. Surprisingly, almost none $(0.3 \%)$ of the infants in Chad were exclusively breastfed.

Likewise, $72.3 \%$ of infants $0-5$ months were predominantly breastfed. Age-disaggregated values indicated that the figure was $87.8 \%$ among young infant $0-1$ month, whereas the corresponding proportions for infants 2-3 $(76.8 \%)$ and $4-5(55.2 \%)$ months were substantially lower.

Figure 3 shows the pattern of exclusive and predominant breastfeeding across 0-23 months of age. Exclusive breastfeeding sharply declines from $64 \%$ around the time of birth to $20 \%$ at the end of the fifth month of age. Similarly predominant breastfeeding declines from $89.6 \%$ to $50.6 \%$ between the two time points (figure 3 ).

\section{Continued breastfeeding at 1 year and 2 years}

In SSA a significant proportion of infants and young children remain breastfed through the first and second years of age. Continued breastfeeding at 1 year (12-15 months of age) was $89.5 \%$, whereas at 2 years (20-23 months) was $53.7 \%$ (figure 2). Continued breastfeeding at 2 years was relatively higher $(>80 \%)$ in Rwanda, Burkina Faso, Malawi, Burundi and Mozambique. Conversely, the lowest level was observed in Gabon (4.8\%). 


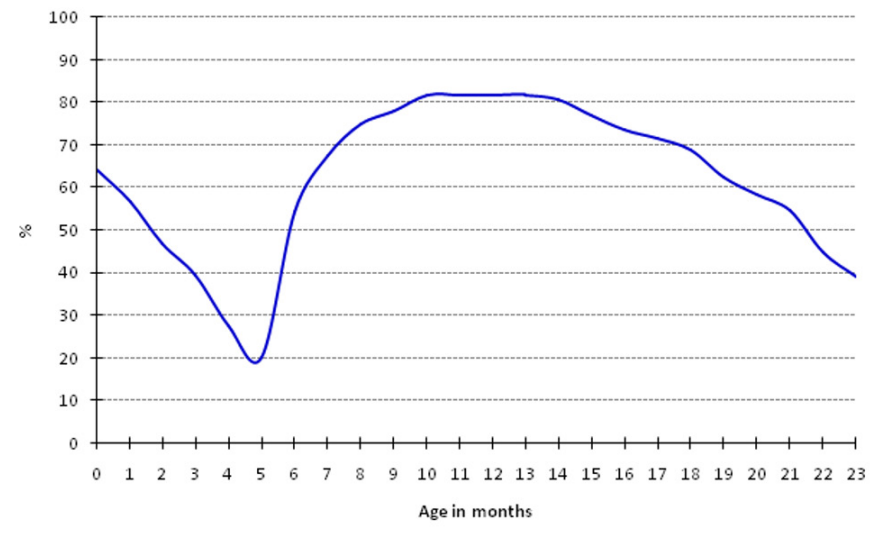

Figure 4 Age-appropriate breastfeeding among children 0-23 months of age in 32 Sub-Saharan African countries, 2010-2016.

Figure 3 shows the proportion of children 0-23 months of age who were breastfed in the preceding day of the survey. In the first 12 months of age, more than $90 \%$ of infants were breastfed. At the age of 18 and 23 months, still about three-fourths (74\%) and one-third (42\%), respectively, were breastfed.

\section{Introduction of complementary foods}

Among 16775 infants 6-8 months of age, two-thirds $(69.3 \%)$ received solid, semisolid or soft foods in the preceding day of the survey (figure 2). The proportion of children who received food in the preceding day starts to exponentially increase from the second month of age onwards. On the other hand, about $10 \%$ and $5 \%$ of children 18 and 23 months of age did not receive solid, semisolid or soft foods in the previous day (figure 3). Country-specific estimates suggested that more than 90\% of infants 6-8 months of age in Tanzania, Mozambique, Congo Republic and Zimbabwe received food in the previous day, whereas less than $50 \%$ did the same in Guinea, Liberia, Mali and Burkina Faso.

\section{Age-appropriate breastfeeding}

More than half $(60.3 \%)$ of the infants and young children 0-23 months had age-appropriate breastfeeding. Among children 6-23 months, age-appropriate breastfeeding (ie, proportion of children who received breast milk, as well as solid, semisolid or soft foods) was $66.9 \%$. Figure 4 shows the pattern of age-appropriate breastfeeding between 0 and 23 months. The indicator sharply declines between 0 and 5 months, increases again between 6 and 12 months, and then declines. By the end of the second year of age, about $40 \%$ of the children had age-appropriate breastfeeding. The indicator was relatively high $(>70 \%)$ in Rwanda, Burundi, Malawi, Zambia, Tanzania and Kenya. Conversely, it falls below 30\% in Gabon (figure 4).

\section{Meal frequency, dietary diversity and acceptable diet}

The meal frequency and dietary diversity patterns were assessed among children 6-23 months of age. Less than half $(41.9 \%)$ of the children received solid, semisolid or soft foods the minimum recommended number of times or more in the previous day (figure 2). The WHO guideline sets different meal frequency standards for breastfed and non-breastfed children. Breastfed children (43.5\%) were found to be more likely to receive adequate number of meals than the non-breastfed children (34.9\%). Proportions who had received the recommended number of meals over the preceding day were $38.5 \%$ in infants $6-11$ months, $45.0 \%$ in children $12-17$ months and $43.3 \%$ in children 18-23 months. The indicator was relatively higher $(>50 \%)$ in Gambia, Lesotho, Nigeria and Niger. Conversely, it falls below 30\% in Malawi, Mali, Angola and Burundi.

The mean $( \pm \mathrm{SD})$ dietary diversity score computed out of the standard seven food groups was $2.29( \pm 1.59)$, and only $21.0 \%$ of the children $6-23$ months received from four or more food groups over the previous day. Proportions of children who met the minimum standard for dietary diversity among children 12-17 months (24.0\%) and $18-23$ months $(26.0 \%)$ were relatively higher than that of younger infants (13.2\%). Proportions of children who met the minimum dietary diversity remain low (less than 40\%) in all of the studied countries. In Niger, Burkina Faso and Guinea, the indicator falls below $10 \%$.

In the preceding day of the surveys, more than threefourths $(76.3 \%)$ of the children received grains, roots or tubers, and nearly half (44.4\%) received vitamin A-rich fruits and vegetables. Conversely, a smaller proportion of infants and young children consumed flesh foods $(32.4 \%)$, dairy products $(24.5 \%)$, legumes and nuts $(20.8 \%)$, other fruits and vegetables $(18.0 \%)$, and eggs (12.7\%).

A very small proportion $(9.8 \%)$ of infants and young received a minimum acceptable diet. The indicator was more or less comparable for breastfed $(9.8 \%)$ and non-breastfed $(9.7 \%)$ children. Among infants $6-11$ only $6.3 \%$ received a minimum acceptable diet. Of children 12-17 and 18-23 months old, the corresponding figures were $12.3 \%$ and $11.6 \%$, respectively. Across all the countries, the proportion of children who met the minimum acceptable diet was less than $20 \%$.

\section{Consumption of iron-rich or iron-fortified foods}

More than one-third $(37.6 \%)$ of the infants and young children consumed iron-rich or iron-fortified foods including flesh foods, fortified foods designed for infants or infant formula the previous day. Of the total $28.2 \%$ consumed flesh foods only and $9.4 \%$ were given fortified foods. Age-disaggregated figures indicated that consumption of iron-rich or iron-fortified foods increased from $30.0 \%$ in infants aged $6-11$ months old, to $40.4 \%$ in children aged $12-17$ months and $41.5 \%$ in those aged $18-23$ months old. The indicator ranged from $12 \%$ in Ethiopia to $76 \%$ in Gabon.

\section{Milk feeding frequency for non-breastfed children}

The adequacy of milk feeding frequency among non-breastfed children was determined in 29 countries 


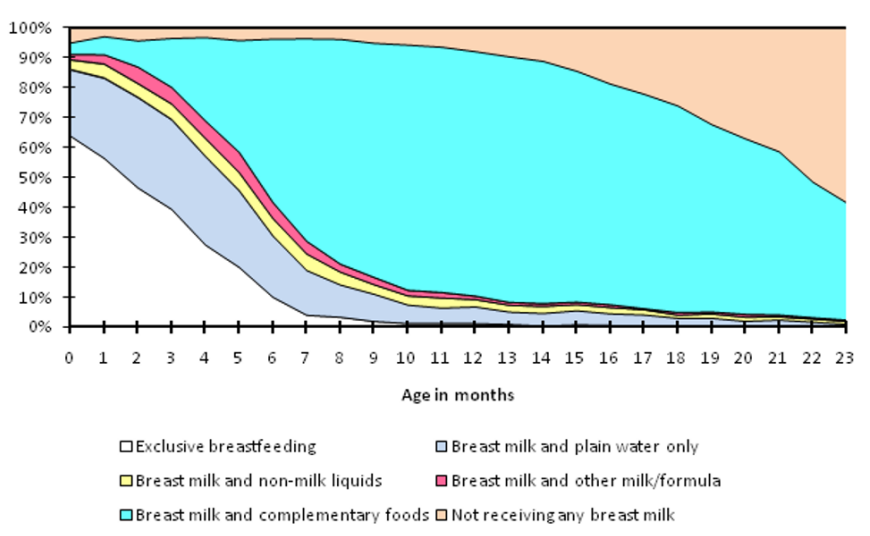

Figure 5 Summary of infant and young child feeding practices by child's age in 32 Sub-Saharan African countries, 2010-2016.

(excluding Gabon, Congo Republic and Cameroon) that have data on the frequency of consumption of milk and infant formula over the previous day. Among infants and young children who were not breastfed, only $15.0 \%$ received the recommended two or more milk feedings. The proportion of non-breastfed children who had at least the minimum milk feeding frequency did not substantially vary between infants and young children aged 6-11 (19.3\%) and 12-17 (19.4\%) months. However, it was lower (12.9\%) among children 18-23 months.

\section{Bottle feeding}

About one-tenth $(12.6 \%)$ of the children 0-23 months were fed with a bottle with a nipple in the previous day. Bottle feeding was relatively higher $(16.6 \%)$ among children 6-11 months. The disaggregated figures for the other age groups were $11.0 \%$ in infants $0-5$ months and $11.7 \%$ among children 12-23 months. Bottle feeding was found to be very common in Mozambique (69.5\%), Gabon $(43.3 \%)$ and Namibia $(35.5 \%)$. Conversely it was low $(<5 \%)$ in Burkina Faso, Niger, Burundi, Tanzania, Togo, Malawi and Zambia.

\section{Feeding practices by age}

Figure 5 summarises the IYCF practices by child's age. Among infants younger than 6 months, proportions who received breast milk alone or along with other liquids sharply decline starting from birth to 6 months of age. Between 0 and 5 months of age, 20\%-30\% of infants received only breast milk and plain water. Between 6 and 12 months of age, significant proportions of children (about 10\%-40\%) remain predominately dependent on breast milk without receiving solid, semisolid or soft foods. The percentage of children who were not receiving any breast milk remains less than $10 \%$ in the first year of age, and it starts to substantially increase after 12 months of age (figure 5).

\section{DISCUSSION}

The study provided a summary of the 14 core and optional IYCF indicators for the SSA based on 32 nationally representative surveys conducted in the region since 2010. It suggested that most of the breastfeeding-related indicators, except exclusive breastfeeding and early initiation of breastfeeding, were in a better situation in the region, while complementary feeding indicators were generally low. The analysis indicated that most of the IYCF indicators largely vary across the countries studied. However, the minimum dietary diversity and minimum acceptable diet indicators were consistently low.

The analysis showed that $41 \%$ of children were exclusively breastfed in the preceding day of the survey, and remarkable variations were observed among the studied countries. According to the WHO guideline for rating of exclusive breastfeeding, of the 32 countries surveyed 2 were in the poor $(0 \%-11 \%), 17$ were in the fair $(12 \%-$ $49 \%), 13$ were in the good $(50 \%-89 \%)$ categories, while none were in the very good category $(90 \%-100 \%) .{ }^{21}$ Additional studies might be needed to explore why countries like Chad and Gabon are not performing well in terms of exclusive breastfeeding practice. In these countries, interventions to improve exclusive breastfeeding practice are critically needed.

The study indicated that predominant breastfeeding is reasonably high $(72 \%)$, and there is huge discrepancy between predominant and exclusive breastfeeding practices between 0 and 5 months of age. Especially provision of breast milk with plain water is found to be a common practice in SSA. The big discrepancy between predominant and exclusive breastfeeding practices in the study may suggest that interventions targeting at discouraging provision of plain water to infants can increase exclusive breastfeeding rate by as high as 30 percentage points.

Although most of the core and optional IYCF indicators are determined based on the current status data of the children, two indicators-'early initiation of breastfeeding' and 'children ever breastfed'-require historical information about deceased and living children born in the preceding 24 months of the survey. ${ }^{14}$ However, frequently surveys determine the two indicators only based on the data of living children. In the current analysis it was observed that the aforementioned two indicators may vary by more than 20 percentage points between living and deceased children, in favour of living children. Accordingly, excluding historical data of deceased children from IYCF surveys may significantly overestimate the two indicators, especially when the level of child mortality in the population is high.

Meeting the minimum standards for complementary feeding is challenging in SSA and other low-income and middle-income regions of the world. In this study only $42 \%$ of children $6-23$ months met the minimum recommended meal frequency, whereas even smaller proportions satisfied the benchmarks for dietary diversity $(21.0 \%)$ and acceptable diet (10\%). A study based on nationally representative data from eight South Asian countries concluded the same. The study estimated the minimum standards for meal frequency $(48 \%)$, dietary diversity $(33 \%)$ and acceptable diet $(21 \%)$ in the South 
Asian region were only met by a smaller proportion of children 6-23 months of age. ${ }^{22}$

In Africa, as the vast majority of babies are breastfed, little programmatic attention has been given so far to non-breastfed children. Yet this analysis indicated that about $15 \%$ of children $6-23$ months of age were not breastfed in the preceding day, and non-breastfed children were largely exposed to suboptimal feeding practices. Only $35 \%$ of such children met the minimum required meal frequency, and merely $15 \%$ received at least two milk feedings during the previous day. ${ }^{14} 23$ The finding may indicate that, on top of promoting breastfeeding of children for 2 years of age and beyond, optimal feeding practices for non-breastfed children should be advocated.

WHO recommends that in the estimation of the indicator 'consumption of iron-rich or iron-fortified foods' among children 6-23 months, three dietary sources should be considered: animal source flesh foods, commercially fortified foods with iron that are specially designed for infants and young children, and foods that are fortified at home with iron. However, due to limitation of the data, two specific alterations have been made in this analysis. First, all commercial infant formula and industrially fortified baby foods were assumed to be iron-fortified. Second, household level of iron fortification with micronutrient powder was assumed to be negligible. The alterations might have overestimated or underestimated the iron consumption pattern in the SSA.

In general this study suggested nearly all of the complementary feeding-related indicators are consistently low across the subcontinent. Further, exclusive breastfeeding among children 0-5 months is suboptimal in many countries in the region, including Chad, Gabon, Comoros and Cote d'Ivoire. Enhancing the status of minimum acceptable diet and improving exclusive breastfeeding practice in the first 6 months should be given priority in IYCF programmes. Countries in the region can enhance IYCF-related indicators through multiple strategies. A systematic review suggested that promoting breastfeeding through health professionals, trained volunteers and peers can improve breastfeeding practices. ${ }^{24}$ Nutrition education through front-line health workers and investments in nutrition-specific interventions also help to improve complementary feeding practices including dietary diversity. ${ }^{13}$

The study indicated that $74 \%$ of the infants and young children in SSA are anaemic. Multifaceted factors might have contributed to the remarkably high burden of anaemia in the region. One key factor might be the low dietary diversity and suboptimal consumption of ironrich foods during the complementary feeding period. Further, in the first 6 months of age, most infants in Africa are predominately breastfed, and breast milk is known to contain inadequate amount of iron. Studies suggested, despite being exclusively breastfed, young infants are unlikely to be anaemic because full-term infants have adequate iron stores at birth lasting for 4-6 months. ${ }^{25}{ }^{26}$ However, in low-income and middle-income countries, newborn iron store is likely to be suboptimal due to the high prevalence of maternal anaemia and low prenatal iron supplementation coverage.$^{25}$ Frequent diarrhoea, malaria and other infections among infants and young children can also contribute to the burden. Accordingly, interventions to improve anaemia status, including promotion of maternal iron supplementation, enhancing consumption of diversified diet including flesh foods, improving access to iron-fortified complementary foods and prevention of infections, should be given priority in the region.

One strength of the current study is that it is based on large-scale, recent and nationally representative surveys from 32 countries that contribute to more than $85 \%$ of the SSA population. Further it provided a summary of all core and optimal IYCF indicators (except the median duration of breastfeeding) that have not been available at such scale before. The presented indicators include 'consumption of iron-rich or iron-fortified foods' and 'milk feeding frequency for non-breastfed children', which are not typically included in the DHS reports. The sample size was also huge, and it allowed for precise estimation of indicators including timely introduction of foods and continued breastfeeding at 1 and 2 years, which are defined in narrow age ranges. Further, in line with the WHO guideline, the study provided age-disaggregated figures for all of the indicators with reasonable precision.

However, there were some limitations and possible biases to this study. Although the original surveys represented more than $85 \%$ of the SSA population, there is no guarantee that the IYCF profile of the non-represented countries is similar to the studied ones. Hence, generalisability of the findings to the entire SSA might be theoretically dubious. Further, due to the cross-sectional nature of the original studies, indicators related to complementary feeding practice, especially dietary diversity and consumption of iron-rich foods, might have been affected by seasonality bias. Finally, as described above, the indicator 'consumption of iron-rich or iron-fortified foods' might have been overestimated or underestimated.

\section{CONCLUSION}

The study provided a summary of 14 core and optional IYCF indicators for the SSA region. Most of breastfeeding-related indicators, except exclusive breastfeeding and early initiation of breastfeeding, were found to be in a relatively better situation. Yet complementary feeding indicators were generally low. The analysis indicated that most of the IYCF indicators largely vary across the studied countries. Yet the minimum dietary diversity and minimum acceptable diet indicators remained consistently low across all the countries.

Acknowledgements The author acknowledges the DHS Program for granting access to the data.

Contributors SG accessed and analysed the data and developed the manuscript. 
Funding The authors have not declared a specific grant for this research from any funding agency in the public, commercial or not-for-profit sectors.

Competing interests None declared.

Patient consent for publication Not required.

Ethics approval The original surveys were approved by the Institutional Review Board (IRB) of ORC Macro and national-level IRBs of all host countries. Data were collected after taking informed consent from the mothers of the index children. Ethical clearance was not sought for this specific data analysis. However, the primary data were collected in accordance with international ethical standards. The data sets were accessed after taking permission from Measure DHS.

Provenance and peer review Not commissioned; externally peer reviewed.

Data sharing statement The data sets analysed for the study are available from https://dhsprogram.com/data/.

Open access This is an open access article distributed in accordance with the Creative Commons Attribution Non Commercial (CC BY-NC 4.0) license, which permits others to distribute, remix, adapt, build upon this work non-commercially, and license their derivative works on different terms, provided the original work is properly cited, appropriate credit is given, any changes made indicated, and the use is non-commercial. See: http://creativecommons.org/licenses/by-nc/4.0/.

\section{REFERENCES}

1. United Nations Children's Fund, World Health Organization, World Bank, United Nations Population Division. Levels and trends in child mortality report 2017: Estimates Developed by the UN Inter-agency Group for Child Mortality Estimation. New York, Washington and Geneva: UN Inter-agency Group, 2017.

2. Nations U. The millennium development goals report. New York: United Nations, 2015.

3. You D, Hug L, Ejdemyr S, et al. Global, regional, and national levels and trends in under- 5 mortality between 1990 and 2015 with scenario-based projections to 2030: a systematic analysis by the UN inter-agency group for child mortality estimation. Lancet 2015;386:2275-86.

4. Black RE, Victora CG, Walker SP, et al. Maternal and child undernutrition and overweight in low-income and middle-income countries. Lancet 2013;382:427-51.

5. World Bank. Data: Prevalence of stunting, 2015. https://data. worldbank.org/indicator/SH.STA.STNT.ZS. (Accessed on 20 Mar 2018)

6. World Health Organization. The global prevalence of anaemia in 2011. Geneva, Switzerland: World Health Organization, 2015.

7. World Health Organization. Global prevalence of Vitamin A deficiency in populations at risk1995-2005: WHO Global Database on Vitamin A Deficiency. Geneva, Switzerland: WHO, 2015.

8. Andersson M, Karumbunathan V, Zimmermann MB. Global iodine status in 2011 and trends over the past decade. J Nutr 2012;142:744-50.
9. Wessells KR, Singh GM, Brown KH, et al. Estimating the global prevalence of inadequate zinc intake from national food balance sheets: effects of methodological assumptions. PLoS One 2012;7:e50565.

10. Prentice AM, Ward KA, Goldberg GR, et al. Critical windows for nutritional interventions against stunting. Am J Clin Nutr 2013:97:911-8

11. Prendergast AJ, Humphrey JH. The stunting syndrome in developing countries. Paediatr Int Child Health 2014;34:250-65.

12. World Health Organization. Complementary feeding - Report of the global consultation: Summary of guiding principles. Geneva, Switzerland: WHO, 2001.

13. Bhutta ZA, Das JK, Rizvi A, et al. Evidence-based interventions for improvement of maternal and child nutrition: what can be done and at what cost? Lancet 2013;382:452-77.

14. World Health Organization. Indicators for assessing infant and young child feeding practices: Part 1 definitions. Geneva, Switzerland: WHO, 2008.

15. World Health Organization. Indicators for assessing breastfeeding practices: WHO/CDD/Ser/91.14. Geneva, Switzerland: World Health Organization, 1991.

16. The World Bank. Data. 2018. https://data.worldbank.org/region/subsaharan-africa (Accessed on 21 Mar 2018).

17. World Health Organization and International Bank for Reconstruction and Development/The World Bank. Tracking Universal Health Coverage: 2017 Global Monitoring Report. Geneva, Switzerland: WHO, 2017.

18. MEASURE DHS/ICF International. Demographic and Health Surveys methodology: Sampling and household listing manual. Calverton, MD: ICF International, 2012.

19. MEASURE DHS/ICF International. Demographic and Health Survey: Interviewer's manual. Calverton, MD: ICF International, 2012.

20. The DHS program. Data. https://dhsprogram.com/Data/ (Accessed on 21 Mar 2018)

21. World Health Organization. Infant and young child feeding: A tool for assessing national practices, policies and programmes. Geneva, Switzerland: WHO, 2003.

22. Aguayo VM. Complementary feeding practices for infants and young children in South Asia. A review of evidence for action post-2015. Matern Child Nutr 2017;13 Suppl 2:e12439.

23. World Health Organization. Guiding principles for feeding nonbreastfed children 6-24 months of ages. Geneva, Switzerland: WHO, 2005.

24. Balogun OO, O'Sullivan EJ, McFadden A, et al. Interventions for encouraging women to start breastfeeding. 2016. The Cochrane Collaboration https://www.cochrane.org/CD001688/PREG interventions-encouraging-women-start-breastfeeding (Accessed on 20 Sep 2018).

25. World Health Organization. The optimal duration of exclusive breastfeeding: A systematic review. Geneva, Switzerland: WHO, 2002.

26. American academy of pediatrics. Breastfeeding and the use of human milk. Pediatrics 1997;100:1035-9. 